\title{
Plural definite NPs presuppose multiplicity via embedded exhaustification *
}

\author{
Clemens Mayr
}

$Z A S$

\begin{abstract}
There is evidence from bare plurals that strongly suggests that pluralmarking on noun phrases does not exclude singular reference. This paper discusses the problematic consequence that such a view has for the analysis of definite plurals, namely that their multiplicity inference is not straightforwardly predicted. We adduce novel evidence that this inference is a semantic presupposition arising from the application of the definite article to the plural noun phrase and that it cannot be explained away by a presuppositional analysis of number-marking (Sauerland 2003). It is proposed that plural- and singular-marking are scalar items subject to obligatory exhaustification (Ivlieva 2013). We show that global exhaustification is, however, untenable in the case of definite plurals, contra Magri (2014). The semantics of the definite article is shown to force exhaustifiation to occur below itself on the noun phrase directly. Having reached this conclusion for definite plurals makes it possible to drastically simplify the derivation of the multiplicity inference even in bare plurals when compared to competing proposals such as Spector (2007a) and Zweig (2009).
\end{abstract}

Keywords: plural, definite descriptions, presupposition, exhaustification

\section{Plural morphology on bare plurals}

\subsection{Why plural morphology on nouns does not assert multiplicity}

A bare plural gives rise to a multiplicity inference. For (1), for instance, one normally concludes that Paul wrote more than one song.

(1) Paul wrote songs.

From data such as (1) one would be led to believe that plural-marking expresses multiplicity semantically (Link 1983, 1991; Chierchia 1998). As often discussed, however, a bare plural embedded in a downward monotonic environment does not

* I wish to thank Gennaro Chierchia, Franziska Conradts, Maribel Romero, Uli Sauerland, the reviewers for SALT25, and the audiences at SALT25 and at ZAS for helpful comments and suggestions. All errors are my own. The research reported here was funded by DFG grant MA5872/1-1. 
give rise to a comparable multiplicity inference (Krifka 1989; Sauerland, Anderssen \& Yatsushiro 2005; Spector 2007a; Zweig 2009). That is, (2) does not just mean that Paul did not write more than one song, which would be compatible with him having written exactly one song. Rather (2) means that Paul did not write any songs at all. Similarly, the question in (3a) is not about whether Paul wrote more than one song but rather about whether he wrote a song at all. If it were about the former, the answer in (3b) should be fine. Yet it feels unnatural given the question.

(2) Paul didn't write songs.

(3) a. Did Paul write songs?

b. \# No, he wrote just one song.

From this it follows that plural morphology on bare nouns and therefore on noun phrases (NPs) more generally does not assert multiplicity. That is, plural must denote a function that when applied to an NP-denotation returns a function that can be true of individuals with singular reference too. Moreover, the multiplicity inference observed in examples without embedding should be defeasible, given its disappearance in downward monotonic environments.

\subsection{The semantics of plural and the pragmatics of the multiplicity inference}

This can be formalized as follows. The domain of entities $D_{e}$ contains not just singular individuals, the atoms, but also collections thereof, the pluralities. That is, given a set of individuals $D$ the domain of entities $D_{e}$ is the set consisting of all the possible collections of individuals there are - that is, it is a set of sets of individuals. Following Schwarzschild (1994) atomic individuals are equated with their single elements. The remaining, non-singleton sets in $D_{e}$ are the plural individuals: ${ }^{1}$

$$
\begin{aligned}
& \text { a. } D=\{a, b, c\} \\
& \text { b. } \begin{aligned}
D_{e} & =\{\{a\},\{b\},\{c\},\{a, b\},\{a, c\},\{b, c\},\{a, b, c\}\} \\
& =\{a, b, c,\{a, b\},\{a, c\},\{b, c\},\{a, b, c\}\}
\end{aligned}
\end{aligned}
$$

Plural-marking on nouns can then be defined as in (5). This is the function that when applied to a predicate of type $\langle e, t\rangle$ gives back a function defined for both atomic and non-atomic individuals $X$ and delivers 1 if and only if all atoms in $X$ make the predicate true.

$$
[[\mathbf{p l}]]=\lambda f \in D_{\langle e, t\rangle} \cdot \lambda X \in D_{e} \cdot \forall x[x \in X \rightarrow f(x)=1]
$$

1 In the following, capital letters like $X$ stand for both atomic and non-atomic individual variables, and non-capital letters like $x$ stand for atomic ones only. 
We assume that lexical predicates of type $\langle e, t\rangle$ like song are true only of atomic individuals. That is $[\text { song }]^{w}$ has the denotation in (6a). Applying the denotation of plural-marking to this function gives us the function in (6b), which is true of either an atomic or a non-atomic individual as long as all its members are song-atoms.

a. $[$ [song $]]^{w}=\lambda x . x$ is a song in $w$

b. $[[\text { song-pl }]]^{w}=\lambda X . \forall x[x \in X \rightarrow x$ is a song in $w]$

Moreover, assume for simplicity that bare plurals are headed by a silent indefinite article denoting an existential quantifier, as in (7). Note that this quantifier ranges over both atomic and non-atomic individuals.

$$
[[\text { indef }]]=\lambda f \in D_{\langle e, t\rangle} \cdot \lambda g \in D_{\langle e, t\rangle} \cdot \exists X[f(X)=1 \wedge g(X)=1]
$$

Finally, to say that Paul wrote a plurality of songs means that there is a plurality of songs such that Paul wrote each atomic individual in it. As a consequence of this we need a distributive operator applying to verbal predicates of type $\langle e, t\rangle$ and predicates derived by movement (Link 1983; Schwarzschild 1996), as in (8). ${ }^{2}$

$$
[[\mathbf{D I S T}]]=\lambda f \in D_{\langle e, t\rangle} \cdot \lambda X \in D_{e} \cdot \forall x[x \in X \rightarrow f(x)=1]
$$

Given these assumptions, the most straightforward LF for (2) above, repeated in (9) is as in (10a) where the bare plural has been moved for type reasons to a position below the negation but above the distributive operator. The truth-conditions are then as in (10b). Given that the existential quantifier ranges over both atomic and non-atomic individuals, this means that Paul did not write any songs at all, as desired.

(9) Paul didn't write songs.

(10) a. [ not [ indef song-pl [ DIST [ 2[ Paul wrote t 2 ]]]]]

b. $[[(\mathbf{1 0 a})]]^{w}=1$ iff $\neg \exists X\left[[[\text { song-pl }]]^{w}(X) \wedge \forall x[x \in X \rightarrow\right.$ Paul wrote $x$ in $\left.w]\right]$

Clearly (1), repeated as (11), will then have the LF and the truth-conditions in (12a) and (12b), respectively. (12b) simply says that there is a song individual written by Paul. It does not require that Paul wrote more than one song. That is, there is no multiplicity inference derived for (11) either.

Paul wrote songs.

2 Given that we have seen that plural morphology does not assert multiplicity, the entries for plural morphology and the distributive operator are identical, contra Link $(1983,1991)$ where plural morphology is taken to assert multiplicity. We could take them to be both instances of Link's *-operator. For reasons of perspicuity I will continue to refer to them differently. 
Multiplicity via embedded exhaustification

a. [ indef song-pl ] [ DIST [ 2[ Paul wrote $\left.\left.\left.t_{2}\right]\right]\right]$

b. $[[(\mathbf{1 2 a})]]^{w}=1$ iff $\exists X[[\text { [song-pl }]]^{w}(X) \wedge \forall x[x \in X \rightarrow$ Paul wrote $x$ in $\left.w]\right]$

There is some disagreement in the literature on how exactly the observed multiplicity inference of (11) is to be derived (see Sauerland et al. 2005; Spector 2007a; Zweig 2009 a.o. and the discussion below). For the moment it suffices to observe that (13) could be an alternative that is strictly stronger than (11).

Paul wrote exactly one song.

By standard Gricean reasoning the hearer of the latter would therefore come to believe that the speaker is not certain about the truth of the former, i.e., that he is not certain that Paul wrote exactly one song. This could then be further strengthened (Sauerland 2004) to the inference that the speaker is certain that Paul did not write exactly one song, yielding the multiplicity inference. In the case of a downward monotonic environment the entailment relations are reversed and no strengthening occurs.

\section{Arguments for a semantic presupposition of definite plurals}

\subsection{An issue with definite plurals}

We have seen evidence that plural morphology on nouns does not assert multiplicity. Together with the standard presuppositional analysis of the definite article, this has the consequence that (14a) and (14b) are both defined and true in a situation where there is exactly one song and Paul wrote that song (e.g., Heim 1994). Intuitively, this seems to be a problematic result.

a. Paul wrote the song.

b. Paul wrote the songs.

Let us see why this problematic prediction is made. In order to extend the presuppositional treatment of definite descriptions to definite plurals, the definite article needs to be defined as a kind of maximality operator, as done in Sharvy (1980) and Link (1983): this definite article is only defined for predicates for which there is a maximal group of individuals all of whose atomic members make that predicate true. In case there is only one atomic individual making the predicate true, the maximal group is identical to that one individual. When defined, the definite article returns that maximal group. ${ }^{3}$

3 Note that if universal quantification where not restricted to atomic individuals, (15) would run into problems in case more than one atomic individual, say a group $\{a, b, c\}$, makes the predicate true. 


$$
\begin{array}{r}
[\text { the }]]=\lambda f \in D_{\langle e, t\rangle}: \\
\cdot \exists ! X[f(X)=1 \wedge \forall x[f(x)=1 \rightarrow x \in X]] \\
\cdot X[f(X)=1 \wedge \forall x[f(x)=1 \rightarrow x \in X]]
\end{array}
$$

Assume the following LFs for the sentences in (14a) and (14b):
a. [ the song ] [ DIST [ 2[ Paul wrote $t_{2}$ ]]]
b. [ the song-pl ] [ DIST [ 2[ Paul wrote $\left.\left.\left.t_{2}\right]\right]\right]$

Now, given that nouns with plural morphology denote functions that are defined for both atomic and non-atomic individuals, the definite article delivers either the one atomic individual making that function true or the maximal non-atomic one all of whose atomic members do. More concretely, recall once more the denotations of the definite singular and of the definite plural, repeated for convenience in (17a) and (17b), respectively. The former is only defined for atomic individuals, whereas the latter is defined for atomic and non-atomic individuals alike. The definite article applied to (17a), on the one hand, presupposes that there is a unique atomic song. Consequently, (16a) is only defined in situations where there is such a unique song. The definite article applied to (17b), on the other hand, presupposes that there is a maximal song individual. That is, (16b) is defined in both situations where there is a unique song and in situations where there are multiple songs.

a. $[$ song $]]^{w}=\lambda x . x$ is a song in $w$

b. $[$ [song-pl $]]^{w}=\lambda X . \forall x[x \in X \rightarrow x$ is a song in $w]$

Assuming now that we are in a situation with only one song being salient, it follows that both the presupposition of sentence (14a) and of sentence (14b) is satisfied. In other words, both should be felicitous utterances. Yet sentence (14b) is odd in case there is only one song. In other words, the semantics for plural on NPs introduced in light of the behavior of bare plurals runs into issues with definite plurals.

\subsection{A presuppositional semantics for number-marking?}

Independently of the facts discussed above, Sauerland (2003) introduces a new semantics for number morphology on NPs (also see Sauerland et al. 2005). He suggests that the LFs for the sentences in (14a) and (14b) look as in (18a) and (18b), respectively. On top of the definite NPs there is either singular or plural morphology attached. Inside the NP itself has Link's (1983) *-operator attached.

The reason is that there would now be non-atomic individuals, e.g., $\{a, b\}$, making the predicate true which are not members of the maximal group $\{a, b, c\}$. (15) could then never pick out a non-atomic individual. Since we are quantifying over atomic individuals only, however, and these are moreover equated with their single members, this issue does not arise. Thanks to an anonymous reviewer who asked me to comment on this. 
a. [ sg [ the *song ]] [ DIST [ 2[ Paul wrote $\left.\left.\left.t_{2}\right]\right]\right]$

b. [ pl [ the *song ]] [ DIST [ 2[ Paul wrote $t_{2}$ ]]]

The semantics of the *-operator is the same as the one for plural marking assumed so far. See footnote 2 for discussion. This also means that the denotation of the NP in (18b) is the same as the one assumed so far for the NP with plural morphology on it, namely (20). The definite article applying to (20) delivers the maximal individual making the predicate true if such an individual exists.

$$
\begin{aligned}
& {[[*]]=\lambda f \in D_{\langle e, t\rangle} \cdot \lambda X \in D_{e} . \forall x[x \in X \rightarrow f(x)=1]} \\
& {[[* \text {-song }]]^{w}=\lambda X . \forall x[x \in X \rightarrow x \text { is a song in } w]}
\end{aligned}
$$

The actual number-marking according to Sauerland, however, occurs outside the DP, namely by singular and plural. Extending Cooper's (1979) presuppositional semantics for gender features on pronouns (also see Heim \& Kratzer 1998; Heim 2008 a.o.) to $\phi$-features in general on DPs, Sauerland assumes the lexical entries in (21). Plural denotes the identity function on the domain of entities, whereas singular denotes the identity function on the domain of atomic individuals.

a. $[[\mathbf{s g}]]=\lambda X \in D_{e}: X$ is atomic.$X$

b. $[[\mathbf{p l}]]=\lambda X \in D_{e} . X$

Now, clearly [[sg] is only defined for DPs that denote atomic individuals. That is, it can only apply to [the *-song $]]^{w}$ if it denotes an atomic individual, which is the case only if it maps exactly one individual to 1 . This accounts for the fact that (14a) is only usable if there is exactly one song that Paul wrote. [[pl]], however, can apply both to DPs that denote atomic individuals and to DPs that denote non-atomic ones. In other words, it appears that (14b) even under the LF in (18b) should be utterable in both situations where Paul wrote exactly one song and in situations where he wrote more than one.

In contrast to before, however, there is now a way to block (14b) from being used when Paul wrote exactly one song. Following Heim (1991), Sauerland et al. (2005) make use of the principle of Maximize Presupposition (MP, also see Percus 2006; Chemla 2008; Singh 2011; Schlenker 2012 a.o.). As (22) makes clear, this principle requires that out of two sentences which are presuppositional alternatives and which are contextually equivalent, the one with the stronger presuppositions must be used if its presuppositions are met in the context. Two sentences $\phi$ and $\psi$ are equivalent given a context set $c$ only if $\{w \in c:[[\phi]](w)=1\}=\{w \in c:[[\psi]](w)=1\}$.

\section{Maximize Presupposition}

If $\phi$ and $\psi$ are presuppositional alternatives to each other, $\phi$ and $\psi$ are contextually equivalent, and $\psi$ has stronger presuppositions than $\phi$, then if the context set $c$ satisfies the presuppositions of $\psi, \psi$ must be used in $c$. 
We define the ancillary notion of presuppositional alternative as follows:

\section{(23) Presuppositional alternatives}

The presuppositional alternatives of a sentence $\phi$ are derived by replacing one or more lexical item in $\phi$ with its lexical alternative.

Assume that singular and plural are lexically marked as being alternatives with respect to each other. Only the former contributes a presupposition. Then two sentences $\phi$ and $\psi$ count as presuppositional alternatives with respect to singular and plural if they only differ in the occurrence of singular and plural morphology on a DP. Consider now what happens when one utters (14a) or (14b) in a context where there is exactly one song. The two sentences are contextually equivalent. Since the sentences are, however, also presuppositional alternatives and the presuppositions of (14a) are stronger than those of (14b), MP dictates that the former be used. This has the consequence that $(14 \mathrm{~b})$ is felt to be degraded in such a context. ${ }^{4}$

\subsection{Against a presuppositional semantics for number in general}

Note that strictly speaking a presuppositional analysis of number together with MP only derives the degradedness of (14b) in a context with only one song, but it does not attribute a multiplicity inference to it. However, Sauerland et al. (2005) argue that given the fact that (14b) is the weaker presuppositional alternative an implicated presupposition is derived in cases in which it is usable according to which the presupposition of the stronger (14a) is false. This then amounts to a multiplicity inference, albeit one that should be defeasible given that it is derived in the pragmatics. There is one type of situation in which this inference is systematically not derived. To see when this is the case, consider the logic of MP in the case of definite NPs with number marking once more: if in principle both the definite singular and the definite plural alternatives could be used, the speaker should opt for the former whenever the context satisfies its presupposition. If the context does not satisfy this presupposition, he should choose the definite with plural marking. As a consequence we expect that in a context where it is only established that there is an entity making the denotation of the NP true - that is, a context where there could

4 Since the indefinite article and the definite article are also marked as lexical alternatives (Heim 1991), the full set of presuppositional alternatives looks as in (i). Given that the indefinite article does not contribute a presupposition, it follows that even when one considers the full set in (i), MP will choose (14a) in a context with exactly one song.

(i) $\operatorname{Alt}(14 \mathrm{a})=\operatorname{Alt}(14 \mathrm{~b})=\{$ Paul wrote the song, Paul wrote the songs, Paul wrote a song, Paul wrote songs 
be either exactly one atomic individual or several ones of which the NP denotation holds - the speaker should choose a definite with plural marking.

Consider the examples in (24) in the context given. In that context it is known that at least one song was written by Paul. A speaker cannot utter a definite singular as in (24a) referring to that song entity. The reason for this is clear: given the context Paul might have well written more than one song. Therefore the combination of the presuppositions of the singular and the definite article that there be exactly one song are not satisfied in the context. But in that case MP does not dictate anymore that singular should be used over plural, and we expect (24b) to become acceptable, contrary to fact.

Context: It is common belief that Paul either wrote exactly one song or several ones.

a. \#The song is good.

b. \#The songs are good.

This problem turns out to be fully general. MP must also apply in embedded contexts (Percus 2006; Singh 2011; Schlenker 2012). In particular, let us adopt Singh's suggestion that MP when checking whether a given lexical alternative is appropriate, applies at the level of the local context of the constituent embedding that lexical alternative, as stated in (25). Unembedded sentences become special cases of (25) in the sense that the local context of such a sentence is simply the global one.

\section{Localized Maximize Presupposition}

If $\phi$ and $\psi$ are presuppositional alternatives to each other, $\phi$ and $\psi$ are contextually equivalent, and $\psi$ has stronger presuppositions than $\phi$, then if the local context $c$ satisfies the presuppositions of $\psi, \psi$ must be used in $c$.

As a way of illustration, consider the examples in (26). The antecedents of the conditionals make it clear that the global context does not entail there are any songs written by Paul at all. Nevertheless the definite singular must be used over the plural one. The reason for this is that the local context for the consequent of the conditional is the global context intersected with the antecedent (Heim 1983; Beaver 2001; Schlenker 2009). This local context therefore entails that Paul wrote a song. If the indefinite moreover introduces an atomic song individual as a discourse referent, the presupposition of the definite singular is satisfied in its local context. By localized MP it is therefore the definite singular that must be used and not the plural one. Thereby the contrast is explained. ${ }^{5}$

5 Conversely, if the antecedent of the conditional has a bare plural instead of a singular indefinite, only the definite plural can be used in the consequent, as (ii) shows. This would be due to the fact that now 
(26) a. If Paul wrote a song, the new song will be good.

b. \# If Paul wrote a song, the new songs will be good.

These facts seemingly support the presuppositional analysis of number. But now consider the data in (27). The antecedents make it clear that at least one song and possibly more were written by Paul. Therefore the local context of the consequent does not satisfy the presupposition of the definite singular. By localized MP, the definite plural should now become usable, contrary to fact. This is unexpected on a presuppositional analysis of number coupled with MP.

(27) a. \#If Paul wrote either several songs or just one, the new song is good.

b. \#If Paul wrote either several songs or just one, the new songs are good.

Parallel results obtain for conjunctions, as (28) shows. The local context of the second conjunct in a conjunction is the global one intersected with the first conjunct (see the works cited above for conditionals). Since the local context of the second conjunct in (28) only entails that Paul wrote at least one song and possibly several ones, the definite plural should again be possible. Again, this is not what we find. ${ }^{6}$

a. \# Paul might have only one new song, and he will play the new song tonight.

b. \# Paul might have only one new song, and he will play the new songs tonight.

Consider next the case of disjunction in (29).

a. \# Either Paul did not write several new songs and he also did not write exactly one, or the new song is too bad to be recorded.

b. \# Either Paul did not write several new songs and he also did not write exactly one, or the new songs are too bad to be recorded.

Beaver (2001) and Schlenker (2009) argue that the local context of the second disjunct conforms to the global context intersected with the negation of the first

the presupposition of the definite singular is not satisfied in its local context, whereby MP does not dictate its use any longer.

(ii) a. \# If Paul wrote songs, the new song will be good.

b. If Paul wrote songs, the new songs will be good.

6 (28a) might be acceptable under a different interpretation, namely one where the definite singular refers to the one new song that Paul is sure to have written. 
disjunct. $^{7}$ The negation of the first disjuncts and therefore the local contexts of the second disjuncts in (29) entail that Paul either wrote exactly one new song or several ones. Accordingly, the presupposition of the definite singular is not satisfied. By localized MP the definite plural should become usable. But this is not the case.

\subsection{Intermediate conclusion}

We have seen reasons for believing that plural morphology on bare numerals and other indefinites does not assert multiplicity. As a consequence we expect plural morphology on definite NPs to make a comparable semantic contribution. That is, definite plurals should be able to refer to both atomic and non-atomic individuals depending on the context. This, however, does not seem to be the case in general, as definite plurals appear to carry a strong multiplicity inference. We have also seen that the way to derive this inference cannot be due to a presuppositional analysis of number according to which a definite plural becomes only usable if the presupposition of the definite singular is not satisfied. Such a view would overgenerate as it predicts a definite plural to be acceptable whenever its local context entails that at least one individual and possibly more than one satisfies the denotation of the NP. This, however, is not the case. The underlying reason for this bad prediction is, of course, that a presuppositional analysis of definite plurals even together with MP does not derive a semantic multiplicity inference but only a defeasible pragmatic one. In other words, what the current section teaches us is that the multiplicity inference associated with definite plurals is not defeasible. How does that go together with what we know about the same inference in bare plurals?

7 Geurts (1996) and Simons (2000) suggest that the local context of the second disjunct is simply the global context. See Mayr \& Romoli (To appear) for arguments that this cannot be correct in the general case. Also the contrast between (iii) and (iv) clearly shows that the choice of definite singular or definite plural is dependent on whether the negation of the first disjunct satisfies the presupposition of the former or the latter. This is only consistent with the view espoused in the text.

(iii) a. Either Paul did not write a new song, or the new song is terrible.

b. \# Either Paul did not write a new song, or the new songs are terrible.

(iv) a. \# Either Paul did not write any new songs, or the new song is terrible.

b. Either Paul did not write any new songs, or the new songs are terrible. 


\section{A new account: Predicate-level exhaustification}

In the following I extend the exhaustivity based account of bare plurals (Spector 2007a; Zweig 2009; Ivlieva 2013; Magri 2014) to definite plurals. Following Fox (2007); Chierchia, Fox \& Spector (2012), I assume that exhaustification can take place at embedded levels. In particular, I show that under certain assumptions exhaustification below the definite article, i.e., on the level of the NP, is forced, which makes the correct predictions regarding the multiplicity inference of definite plurals in that they come to presuppose that there is a maximal plurality making the NP denotation true. In a certain sense then Link $(1983,1991)$ and Chierchia (1998) were correct in assuming that plural-marking excludes singular reference, but it does so only in the case of definite plurals and crucially via exhaustification and not lexically.

\subsection{Singular and plural as scalar alternatives}

In contrast to Sauerland's (2003) presuppositional analysis of number-marking, I assume that number-marking occurs on the NP, i.e., where it overtly appears in the case of plural-marking. For simplicity I assume that both singular and plural are lexically expressed. Nothing really hinges on this. It would be possible to maintain that only plural-marking manifests itself lexically, but this would introduce certain complications in the analysis offered below. Singular, on the one hand, is the function applying to an NP-denotation that gives back a function defined for both atomic and non-atomic individuals. It only maps such individuals to 1 , however, if they are atomic and satisfy the NP-denotation. In other words, singular asserts atomicity. Plural, on the other hand, is defined as before. It corresponds to Link's *-operator and accordingly simply requires that all atomic individual elements of a given individual argument satisfy the NP-denotation. In other words, it includes both singular and plural reference:

$$
\begin{aligned}
& \text { a. }[[\mathbf{s g}]]=\lambda f \in D_{\langle e, t\rangle} \cdot \lambda X \in D_{e} . X \in D \wedge f(X)=1 \\
& \text { b. }[[\mathbf{p l}]]=\lambda f \in D_{\langle e, t\rangle} \cdot \lambda X \in D_{e} \cdot \forall x[x \in X \rightarrow f(x)=1]
\end{aligned}
$$

This, of course, means that singular and plural stand in a scalar relation to each other. The denotation of song-sg is the function returning 1 for song atoms only. Thereby the set characterized by its denotation is a subset of the one characterized by the denotation of song-pl:
a. $[$ song-sg $]]^{w}=\lambda X . X$ is a song atom in $w$
b. $[$ [song-pl $]]^{w}=\lambda X . \forall x[x \in X \rightarrow x$ is a song in $w]$ 
Multiplicity via embedded exhaustification

\subsection{Exhaustification}

Following suggestions in the literature by Spector (2007a); Zweig (2009) and in particular Ivlieva (2013) I assume that whenever an NP bears plural-marking - and possibly number-marking more generally - an exhaustivity operator Exh must occur somewhere in the structure. I formulate this requirement as in (32):

\section{Exhaustification requirement}

If an NP bears plural-marking, the NP must be embedded under Exh.

The standard exhaustivity operator is defined as in (33), following Groenendijk \& Stokhof (1984); van Rooij \& Schulz (2004); Fox (2007); Spector (2007b); and Chierchia et al. (2012). It asserts a proposition and negates all the non-weaker alternatives to that proposition. In addition, I assume that there is also an exhaustivity operator, referred to as Exh2 in (34), that applies at the predicate level. This predicate-level exhaustivity operator applied to an NP-denotation yields a function returning 1 for individuals which make the predicate true and which make all nonweaker alternative predicates false. Clearly, the two exhaustivity operators are closely related, and the latter could be derived from the former. I will not engage in this issue here, however.

$$
\begin{aligned}
& \left.\left[\mathbf{E x h}_{A l t}\right]\right]^{w}=\lambda p \in D_{s t} \cdot p(w)=1 \wedge \forall q \in A l t[p \nsubseteq q \rightarrow q(w)=0] \\
& \left.\left[\mathbf{E x h 2}_{A l t}\right]\right]=\lambda f \in D_{\langle e, t\rangle} \cdot \lambda X \in D_{e} \cdot f(X)=1 \wedge \forall g \in A l t[f \nsubseteq g \rightarrow g(X)=0]
\end{aligned}
$$

\subsection{Putting the ingredients together}

Let us assume that the sentence in (35) has the LF in (36). That is, the definite plural is raised above the distributivity operator. Given the exhaustification requirement, an exhaustivity operator must be present in the LF. In (36) exhaustification happens at the predicate-level of the NP-denotation.

(35) Paul wrote the songs.

(36) [ the [ Exh2 ${ }_{\text {Alt }}$ song-pl ]] [ DIST [ 2[ Paul wrote $\left.\left.\left.t_{2}\right]\right]\right]$

Recall that singular and plural are scalar alternatives. In particular, plural is logically weaker than singular. Predicate-level exhaustification of (31b) then gives a function returning 1 for individuals making (31b) but not (31a) true. That is, it gives a function returning 1 for song pluralities only, as defined in (37). Application of the definite article as in (38) presupposes that there is a maximal individual satisfying (37). In other words, it presupposes that there is a maximal song plurality. If defined, it returns that maximal song plurality. Now clearly, definite plurals carry 
a multiplicity presupposition. Accordingly, (36) only has a defined truth-value if there is a maximal song plurality and it has the truth-value 1 only if Paul wrote that song plurality.

$$
\begin{aligned}
& {\left[\left[\operatorname{Exh}_{A l t} \text { [song-pl] }\right]\right]^{w}=\lambda X .[\lambda Y . \forall y[y \in Y \rightarrow y \text { is a song in } w]](X)=1 \wedge} \\
& {[\lambda Y . Y \text { is a song atom in } w](X)=0} \\
& =\lambda X . X \text { is a song plurality in } w \\
& \left(A l t=\left\{[[\text { song-pl }]]^{w},[[\text { song-sg }]]^{w}\right\}\right) \\
& {[[(\mathbf{3 6})]]^{w}=1 \text { iff Paul wrote in } w \text { the maximal song plurality in } w}
\end{aligned}
$$

\subsection{Checking the predictions of the present account}

Let us see what the predictions of the present account are for the data found to be problematic for a presuppositional analysis of number-marking. First, under the present account (40a) presupposes that there is a unique song, which is not satisfied by the context. Therefore (40a) is predicted to be unacceptable. (40b), on the other hand, presupposes that there is a maximal song plurality. Again, this presupposition is not satisfied by the context. Therefore (40b) is again predicted to be unacceptable. It is this latter case, in which the present account differs from the presuppositional analysis of number.

(40) Context: It is common belief that Paul either wrote exactly one song or several ones.
a. \#The song is good.
b. \#The songs are good.

Now, clearly this explanation immediately carries over to the conditional case in (41) repeated from (27) above. The local context of the consequent entails neither the presupposition of the definite singular nor the one of the definite plural. Therefore both are unusable.

(41) a. \#If Paul wrote either several songs or just one, the new song is good.

b. \#If Paul wrote either several songs or just one, the new songs are good.

It should also be pointed out that MP need not be invoked anymore for the choice of definite singular and definite plural in cases where only one of them is acceptable such as (42), repeated from above as well. Here the local context of the consequent 
entails that Paul wrote several songs. ${ }^{8}$ Thus only the presupposition of the definite plural is satisfied, explaining why the definite singular is unacceptable. ${ }^{9}$

a. \# If Paul wrote songs, the new song will be good.

b. If Paul wrote songs, the new songs will be good.

It should also be noted that embedding a definite plural under negation as in (43) does not affect its multiplicity inference according to the present account. The reason is that predicate-level exhaustification again derives the familiar multiplicity inference as a presupposition. Taking negation to be a hole for presuppositions, this becomes an inference of the whole sentence. This is as it should be.

Paul didn't write the songs.

\section{Predictions, consequences, and comparison with other proposals}

\subsection{Global exhaustification?}

At this point, the reader may wonder why we did not use the proposition-level exhaustivity operator defined in (33) in order to derive the multiplicity inference associated with definite plurals. In other words, why did I not assume an LF like (45) for the sentence (44) repeated from above? Such an LF would obviously satisfy the exhaustification requirement on plural-marking.

(44) Paul wrote the songs.

$$
\text { [ } \left.\left.\left.\left.\text { Exh }_{\text {Alt }}\left[\text { the song-pl [ DIST [ 2[ Paul wrote } t_{2}\right]\right]\right]\right]\right]
$$

To see why such an LF would not give the desired outcome consider the entry for the proposition-level exhaustivity operator in (46) once more.

8 On the derivation of the multiplicity inference of bare plurals see the following section.

9 But what about (v)? Here strictly speaking, the local context of the consequent appears to only entail that Paul wrote at least one song. As a consequence neither the presupposition of the definite singular nor that of the definite plural is satisfied. We would therefore predict that both are unacceptable, whereas the definite singular is in fact acceptable. This is, of course, a characteristic behavior of indefinites. What appears to be necessary here is that a singular indefinite introduces an atomic discourse referent (Heim 1982), and similarly for bare plurals. If something along these lines is guaranteed, the definite singular can then pick out that unique salient atomic referent, in the case at hand the unique new song atom.

(v) a. If Paul wrote a song, the new song will be good.

b. \# If Paul wrote a song, the new songs will be good. 


$$
\left[\left[\mathbf{E x h}_{A l t}\right]\right]^{w}=\lambda p \in D_{s t} \cdot p(w)=1 \wedge \forall q \in A l t[p \nsubseteq q \rightarrow q(w)=0]
$$

When applied to a prejacant $p,(46)$ requires that all the non-weaker alternatives to $p$ are false. In order for that to be the case, however, the presuppositions of these non-weaker alternatives have to be satisfied in the first place. The relevant alternative to the prejacent in the case of (45) is the one with the definite singular. This alternative presupposes that there be a unique song in the context. Given the definition of the exhaustivity operator in (46), this means that (45) only has a defined truth-value in case there is exactly one song in the context. Now, given that pluralmarking is weaker than singular-marking in that it includes singular reference the prejacent in (45) is also defined in this situation. In fact, the prejacent and its singular alternative are contextually equivalent. But then it follows that the proposition-level exhaustivity operator cannot exclude the singular alternative. (45) in essence is equivalent to the sentence with the definite singular.

$$
\begin{array}{r}
\left.\left[[(\mathbf{4 5})]^{w}=1 \text { iff }\left[\mathbf{E x h}_{A l t}\left[\text { the song-sg [ DIST [ } 2\left[\text { Paul wrote } \mathbf{t}_{2}\right]\right]\right]\right]\right]^{w}=1 \\
\left(A l t=\left\{\left[\left[\text { the song-sg [ DIST [ } 2\left[\text { Paul wrote } \mathbf{t}_{2}\right]\right]\right]\right]^{w},\right. \\
\left.\left.\left.\left.\left.\left[\text { the song-pl [ DIST [ } 2\left[\text { Paul wrote } \mathbf{t}_{2}\right]\right]\right]\right]\right]^{w}\right\}\right)
\end{array}
$$

It seems that such derivations must be blocked. Otherwise we would derive an unwanted reading for (44). An obvious way to do so is by requiring as in (48) that plural-marking should have a semantic effect when compared to singular-marking.

\section{Strength requirement on plural-marking}

Given a sentence $\phi$ with [NP-pl] in it, $[[\phi]]^{w} \neq[[\psi]]^{w}$ where $\psi$ is just like $\phi$ except that $[\mathrm{NP}-\mathrm{pl}]$ is replaced with [NP-sg] unless $[[\phi]]^{w}$ is the strongest possible interpretation.

With (48) in place, (45) will be blocked as an LF for (44): its interpretation after exhaustification would be equivalent to the interpretation of the alternative with the definite singular after exhaustification. Moreover, this hypothetical interpretation would not be stronger than the one derived by predicate-level exhaustification. In fact, the interpretations are logically independent. Therefore the LF with predicatelevel exhaustification is licensed. This way (44) will always have a multiplicity inference associated with it.

\subsection{Saving global exhaustification with accommodation?}

Given that it is ultimately the presupposition of the alternative with the definite singular that creates the problem for an analysis based on global exhaustification, we might ask whether this issue could be avoided by presupposition accommodation. ${ }^{10}$ In particular, we might imagine that before exhaustification takes place the

10 I thank an anonymous SALT reviewer for raising this question. 
presupposition of the prejacent and its alternatives are factored into their respective assertive components. Following Beaver \& Krahmer (2001) and Fox (2013), assume for simplicity that there is an accommodation operator as defined in (49). This operator when applied to a proposition returns the characteristic function of those worlds in which that proposition is defined and true.

$$
[[\mathbf{A c c}]]=\lambda p \in D_{s t} \cdot \lambda w \in D_{s} \cdot p(w)=1
$$

The LF for our sentence in (44) would then be as in (50a). Here the accommodation operator is applied before global exhaustification. The alternative to the prejacent is now the sentence with the definite singular including itself the accommodation operator. This means that this alternative now asserts that there is a unique song and that Paul wrote it. The prejacent asserts that there is a maximal song entity and that John wrote it. This time exhaustification asserts the latter and negates the former, giving us the truth-conditions in (50b). These truth-conditions are equivalent to saying that there is a maximal plurality of songs and that Paul wrote it. In other words, together with accommodation global exhaustification can derive the correct multiplicity inference for definite plurals.

a. [ Exh $_{A l t}$ [ Acc [ the song-pl [ DIST [ 2[ Paul wrote t 2 ]]]]]]

b. $[[(\mathbf{5 0 a})]]^{w}=1$ iff there is a maximal song entity in $w$ written by Paul $\wedge$ $\neg$ [there is a unique song in $w$ and Paul wrote it in $w]$

$\left(A l t=\left\{\left[\right.\right.\right.$ Acc $\left[\right.$ the song-pl [ DIST [ 2[ Paul wrote $\left.\left.\left.\left.\left.\left.\mathbf{t}_{2}\right]\right]\right]\right]\right]\right]^{w}$, $\left[\left[\right.\right.$ Acc [ the song-sg [ DIST [ 2[ Paul wrote $\left.\left.\left.\left.\left.\left.\left.\left.t_{2}\right]\right]\right]\right]\right]\right]^{w}\right\}\right)$

However, this cannot be the general solution to the problem of definite plurals and their multiplicity inferences. Consider, for instance, the question in (51). Intuitively, this question also presupposes that there is a maximal song plurality. But the accommodation-based account cannot easily derive this.

Did Paul write the songs?

Assume for simplicity Karttunen's (1977) semantics for the question-operator in polar questions:

$$
[[?]]=\lambda p \in D_{s t} \cdot \lambda q \in D_{s t} \cdot q=p \vee q=\lambda w \cdot \neg p(w)
$$

Since the accommodation operator incorporates the presuppositions of the prejacent and its alternatives into their assertive components, the LF in (53a) for (51) will derive a reading that is best paraphrased as 'Is it the case that there is a maximal song plurality and that John wrote it?'. This is clearly not the reading we are interested in for (51) as it does not take it for granted that there is a maximal song plurality. 
a. [ ? [ Exh [ Acc [ the song-pl [ DIST [ 2[ Paul wrote t ${ }_{2}$ ]]]]]]]

b. $[(\mathbf{5 3 a})]^{w}=$

$\lambda p \cdot p=$ there is a maximal song plurality in $w$ and John wrote it $\vee$

$p=\neg$ (there is a maximal song plurality in $w$ and John wrote it)

So the accommodation operator cannot derive the multiplicity inference of definite plurals in question environments. A parallel issue arises for such an account with definite plurals in downward monotonic environments. For these cases then we need predicate-level exhaustification even in an accommodation-based account. ${ }^{11}$

\subsection{Returning to the multiplicity inference of bare plurals}

Consider once more the examples with a bare plural that we started our discussion with, repeated in (54). Given the fact that (54b) does not bear a multiplicity inference, we concluded that plural marking should include singular reference. Now, we said that a presuppositional analysis of number-marking is not on the right track for definite plurals. It follows that we should also adopt an exhaustification-based approach to the multiplicity inference associated with unembedded bare plurals. ${ }^{12}$
a. Paul wrote songs.
b. Paul didn't write songs.

Consider first (54a). Given the exhaustification requirement on plural-marking, we have to ask whether we could apply global exhaustification in this case, i.e., whether the relevant LF could be (55). As Spector (2007a) and Zweig (2009) discuss such an LF faces problems similar to those we observed for global exhaustification in the case of definite plurals. In particular, given the assumption that plural-marking includes singular reference it follows that the denotation of the prejacent in (55) is equivalent to its alternative with the indefinite singular. Both would say that Paul wrote a song. But then exhaustification cannot exlcude anything, and no multiplicity inference is derived for (54a).

[Exh ${ }_{A l t}$ [ indef song-pl [ DIST [ 2[ Paul wrote $\left.\left.\left.\left.\left.t_{2}\right]\right]\right]\right]\right]$

11 Such considerations are in fact also an argument against the use of a version of the exhaustification operator which has accommodation built into it and which is considered as an option for independent reasons by Spector \& Sudo (2014). Moreover, it appears that Magri's (2014) account of definite plurals based on recursive exhaustification runs into similar problems. I have to leave detailed comparison between the accounts for future research.

12 In fact, Spector (2007a) shows that Sauerland et al.'s (2005) MP-based account does not derive the correct results for the multiplicity inference of bare plurals either. 
Now, Spector (2007a) and Zweig (2009) draw different conclusions from this. The former maintains that exhaustification applies globally, but stipulates that the alternative to the prejacent in (55) used for exhaustification is not the alternative with the indefinite singular but rather (56). This requires repeated exhautification.

(56) Paul wrote exactly one song.

Zweig, on the other hand, argues for an event-based semantics where exhaustification takes place before existential closure of open event variables.

The present approach, however, allows for a significant simplification of the derivation of the multiplicity inference in bare plurals by unifying them with the multiplicity inference found with definite plurals. The LF in (55) yields a weaker interpretation than the LF with predicate-level exhaustification in (57a), which requires that Paul wrote more than one song and not just one song. By the strength requirement in (48) only the latter LF is therefore licensed.

a. [ indef [Exh2 ${ }_{\text {Alt }}$ song-pl ]] [ DIST [ 2[ Paul wrote $t_{2}$ ]]]

b. $[[(\mathbf{5 7 a})]]^{w}=1$ iff Paul wrote several songs in $w$

Now, in the case of (54b), global exhaustification as in (58a) is preferred over predicate-level exhaustification, as in (60a). Since negation reverses logical strength, the strongest interpretation is derived by the former LF stating that Paul did not write any song. This LF is thus preferred by the strength requirement.

a. [ $\operatorname{Exh}_{A l t}$ [ not [ indef song-pl [ DIST [ 2[ Paul wrote $t_{2}$ ]]]]]]

b. $[[(\mathbf{5 8 a})]]^{w}=1$ iff Paul did not write any song in $w$

It seems, however, that marginally a weaker interpretation is available for negative sentences as well, as in (59). This reading is derived via predicate-level exhaustification as in (60a) with the truth-conditions in (60b). The required marked intonation is typical for cases of embedded exhaustification leading to weakening.

(59) Paul didn't write songs. He wrote only one song.

(60) a. [ not [[ indef [Exh2 ${ }_{\text {Alt }}$ song-pl ]] [ DIST [ 2[ Paul wrote $\left.\left.\left.\left.t_{2}\right]\right]\right]\right]$

b. $[[(\mathbf{6 0 a})]]^{w}=1$ iff Paul did not write several songs in $w$

Due to space limitations, I must unfortunately leave further investigation of these suggestive remarks and their comparison with the accounts of Spector (2007a) and Zweig (2009) for future research. 


\section{Conclusion}

Discussing novel data, the present paper showed that the multiplicity inference of definite plurals is semantic in nature. I derived this by extending the exhaustificationbased account of plural-marking to definite plurals. In particular, I argued for predicate-level exhaustification in the case of definite plurals. This move opens the door to a radical simplification of the derivation of the multiplicity inference in bare plurals by allowing for predicate-level exhaustification in that case as well. The placement of the exhaustivity operator has been argued to be constrained by considerations regarding the logical strength of possible interpretations.

\section{References}

Beaver, David \& Emiel Krahmer. 2001. A partial account of presupposition projection. Journal of Logic, Language and Information 10. 147-182.

Beaver, David I. 2001. Presupposition and Assertion in Dynamic Semantics. Stanford University: CSLI Publications.

Chemla, Emmanuel. 2008. An epistemic step for anti-presuppositions. Journal of Semantics 25. 141-173.

Chierchia, Gennaro. 1998. Reference to kinds across languages. Natural Language Semantics 6(4). 339-405.

Chierchia, Gennaro, Danny Fox \& Benjamin Spector. 2012. The grammatical view of scalar implicatures and the relationship between semantics and pragmatics. In Paul Portner, Claudia Maienborn \& Klaus von Heusinger (eds.), Semantics: An International Handbook of Natural Language Meaning, vol. 3, Berlin: Mouton de Gruyter.

Cooper, Robin. 1979. The interpretation of pronouns. In Frank Heny \& H. Schnelle (eds.), Syntax and Semantics 10: Selections from the Third Groningen Round Table, 61-92. New York: Academic Press.

Fox, Danny. 2007. Free choice and the theory of scalar implicatures. In Uli Sauerland \& Penka Stateva (eds.), Presupposition and Implicature in Compositional Semantics, 71-120. Basingstoke, New York: Palgrave.

Fox, Danny. 2013. Presupposition projection from quantificational sentences: Trivalence, local accommodation, and presupposition strengthening. In Ivano Caponigro \& Carlo Cecchetto (eds.), From Grammar to Meaning: The Spontaneous Logicality of Language, 201-232. Cambridge: Cambridge University Press.

Geurts, Bart. 1996. Local satisfaction guaranteed: A presupposition theory and its problems. Linguistics and Philosophy 19(3). 259-294.

Groenendijk, Jeroen \& Martin Stokhof. 1984. Studies on the Semantics of Questions 
Multiplicity via embedded exhaustification

and the Pragmatics of Answers. Amsterdam: University of Amsterdam, PhD dissertation.

Heim, Irene. 1982. The Semantics of Definite and Indefinite Noun Phrases: University of Massachusetts, Amherst, PhD dissertation.

Heim, Irene. 1983. On the projection problem for presuppositions. In Daniel P. Flickinger (ed.), WCCFL 2, 114-125. Stanford University, Stanford, California: CSLI Publications.

Heim, Irene. 1991. Artikel und Definitheit. In Arnim von Stechow \& Dieter Wunderlich (eds.), Semantik: Ein internationales Handbuch der zeitgenössischen Forschung, 487-535. Berlin: de Gruyter.

Heim, Irene. 1994. Plurals. Lecture notes for Advanced Semantics, ms. MIT.

Heim, Irene. 2008. Features on bound pronouns. In Daniel Harbour, David Adger \& Susana Béjar (eds.), Phi-Theory: Phi-Features across Modules and Interfaces, 35-56. Oxford, New York: Oxford University Press.

Heim, Irene \& Angelika Kratzer. 1998. Semantics in Generative Grammar. Malden, MA: Blackwell.

Ivlieva, Natalia. 2013. Scalar Implicatures and the Grammar of Plurality and Disjunction: Massachusetts Institute of Technology PhD dissertation.

Karttunen, Lauri. 1977. Syntax and semantics of questions. Linguistics and Philosophy 1(1). 3-44.

Krifka, Manfred. 1989. Nominal reference, temporal constitution and quantification in event semantics. In Renate Bartsch, Johan van Benthem \& Peter van Emde Boas (eds.), Semantics and Contextual Expression, 75-115. Dordrecht: Foris Publications.

Link, Godehard. 1983. The logical analysis of plurals and mass terms: A latticetheoretical approach. In Rainer Bäuerle, Christoph Schwarze \& Arnim von Stechow (eds.), Meaning, Use and Interpretation of Language, Berlin, New York: de Gruyter.

Link, Godehard. 1991. Plural. In Arnim von Stechow \& Dieter Wunderlich (eds.), Semantik: Ein internationales Handbuch der zeitgenössischen Forschung, Berlin: De Gruyter.

Magri, Giorgio. 2014. An account for the homogeneity effects triggered by plural definites and conjunction based on double strengthening. Ms. CNRS, Univ. Paris 8.

Mayr, Clemens \& Jacopo Romoli. To appear. A puzzle for theories of redundancy: Exhaustification, incrementality, and the notion of local context. Semantics and Pragmatics.

Percus, Orin. 2006. Antipresuppositions. Tech. rep. Japan Society for the Promotion of Science.

van Rooij, Robert \& Katrin Schulz. 2004. Exhaustive interpretation of complex 
sentences. Journal of Logic, Language and Information 13. 491-519.

Sauerland, Uli. 2003. A new semantics for number. In Robert B. Young \& Yuping Zhou (eds.), Semantics and Linguistic Theory (SALT) 13, 258-275. Ithaca, NY: CLC Publications.

Sauerland, Uli. 2004. Scalar implicatures in complex sentences. Linguistics and Philosophy 27(3). 367-391.

Sauerland, Uli, Jan Anderssen \& Kazuko Yatsushiro. 2005. The plural is semantically unmarked. In Stephan Kesper \& Marga Reis (eds.), Linguistic evidence, 413434. Berlin: Mouton de Gruyter.

Schlenker, Philippe. 2009. Local contexts. Semantics and Pragmatics 2. 1-78.

Schlenker, Philippe. 2012. Maximize Presupposition and Gricean reasoning. Natural Language Semantics 20. 391-429.

Schwarzschild, Roger. 1994. Plurals, presuppositions and the sources of distributivity. Natural Language Semantics 2(3). 201-248.

Schwarzschild, Roger. 1996. Pluralities. Dordrecht; Boston: Kluwer Academic.

Sharvy, Richard. 1980. A more general theory of definite descriptions. The Philosophical Review 89. 607-624.

Simons, Mandy. 2000. Issues in the Semantics and Pragmatics of Disjunction. New York: Garland.

Singh, Raj. 2011. Maximize Presupposition! and local contexts. Natural Language Semantics 19. 149-168.

Spector, Benjamin. 2007a. Aspects of the pragmatics of plural morphology: On higher-order implicatures. In Uli Sauerland \& Penka Stateva (eds.), Presupposition and Implicature in Compositional Semantics, Palgrave.

Spector, Benjamin. 2007b. Scalar implicatures: Exhaustivity and Gricean reasoning. In Maria Aloni, Alastair Butler \& Paul Dekker (eds.), Questions in Dynamic Semantics, 225-249. Oxford, Amsterdam: Elsevier.

Spector, Benjamin \& Yasutada Sudo. 2014. Presupposed ignorance and exhaustification: How scalar implicatures and presuppositions interact. Ms. Institut Jean Nicod, CNRS-ENS-EHESS University College London.

Zweig, Eytan. 2009. Number-neutral bare plurals and the multiplicity implicature. Linguistics and Philosophy 32. 353-407.

Clemens Mayr

Center for general linguistics (ZAS)

Schützenstraße 18

10117 Berlin

mayr@zas.gwz-berlin.de 